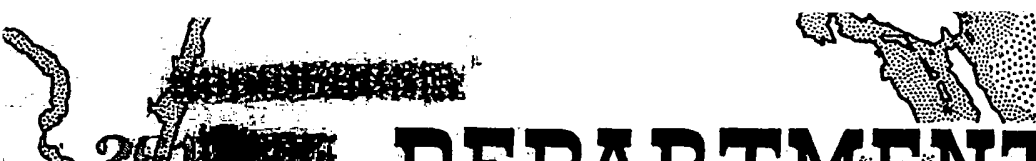

DEPARTMENT OF
DCEANOGRAPHY

UNIYERSITY OF WASHINGTON

551.46865

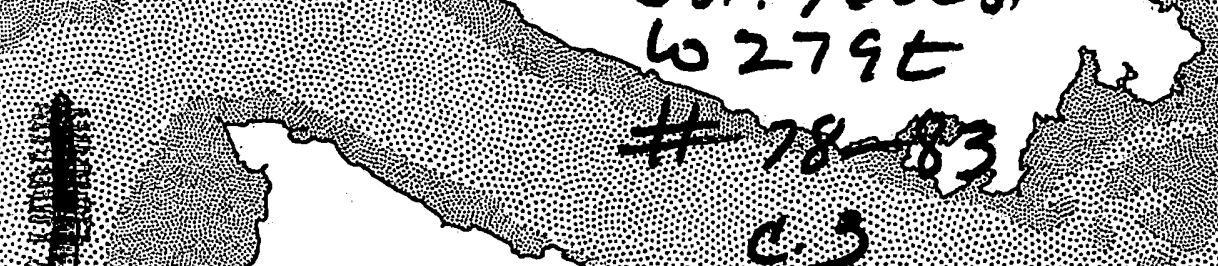

变

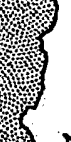

c.s

Tochnieal Roports
Nos. 78, 79, 80,

81, 82, and 83

SompILATION OF ARTICLES

THE OFFICE OF NAVAL RESEARCH

Offico of Naval Regsaarch

Contraet Nonr-A77 (10)

Profot NR 083012
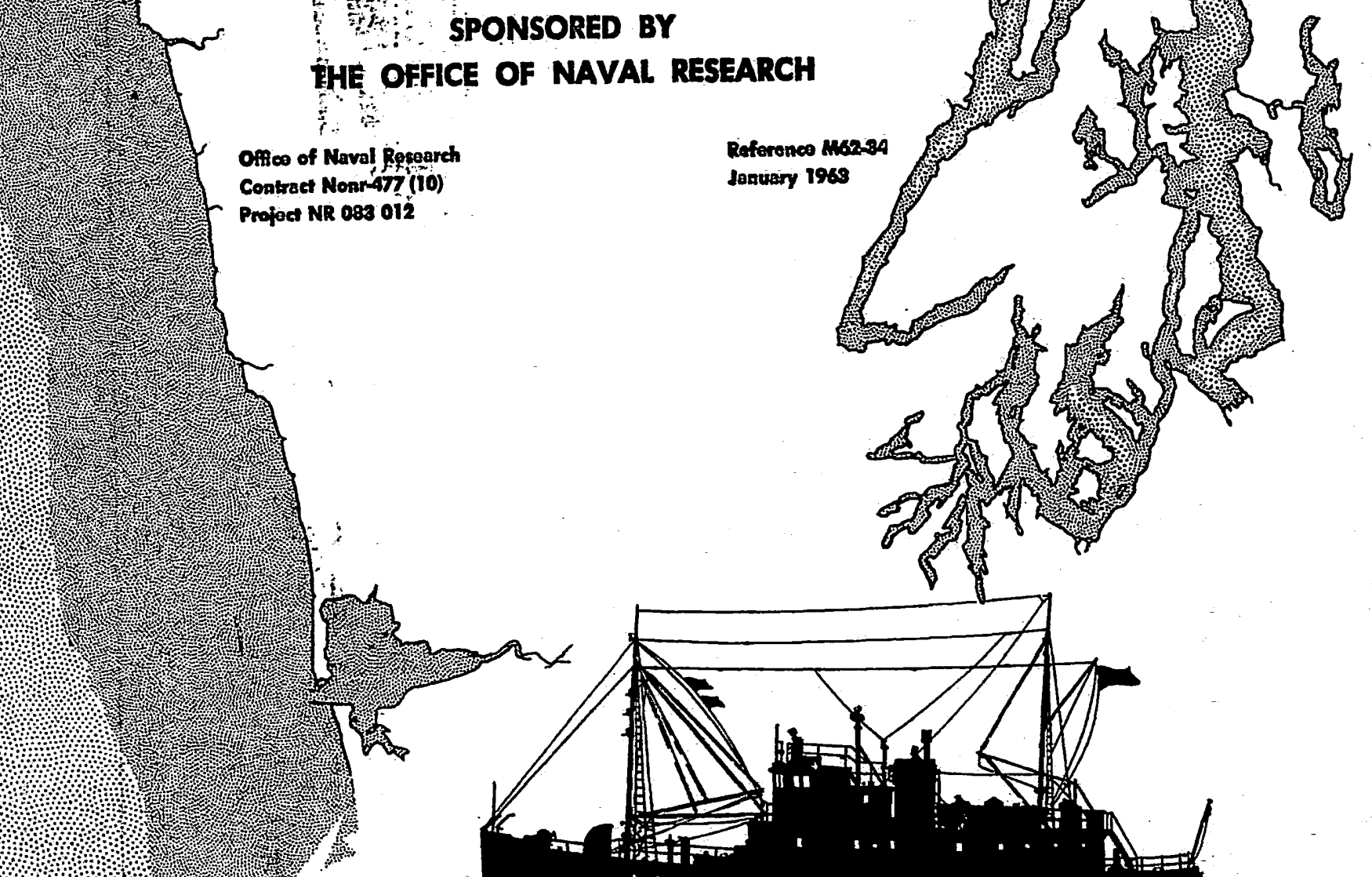

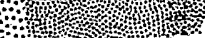
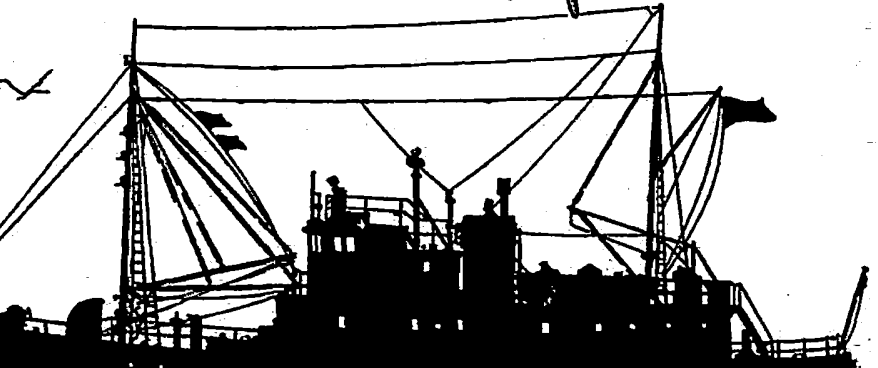
3.
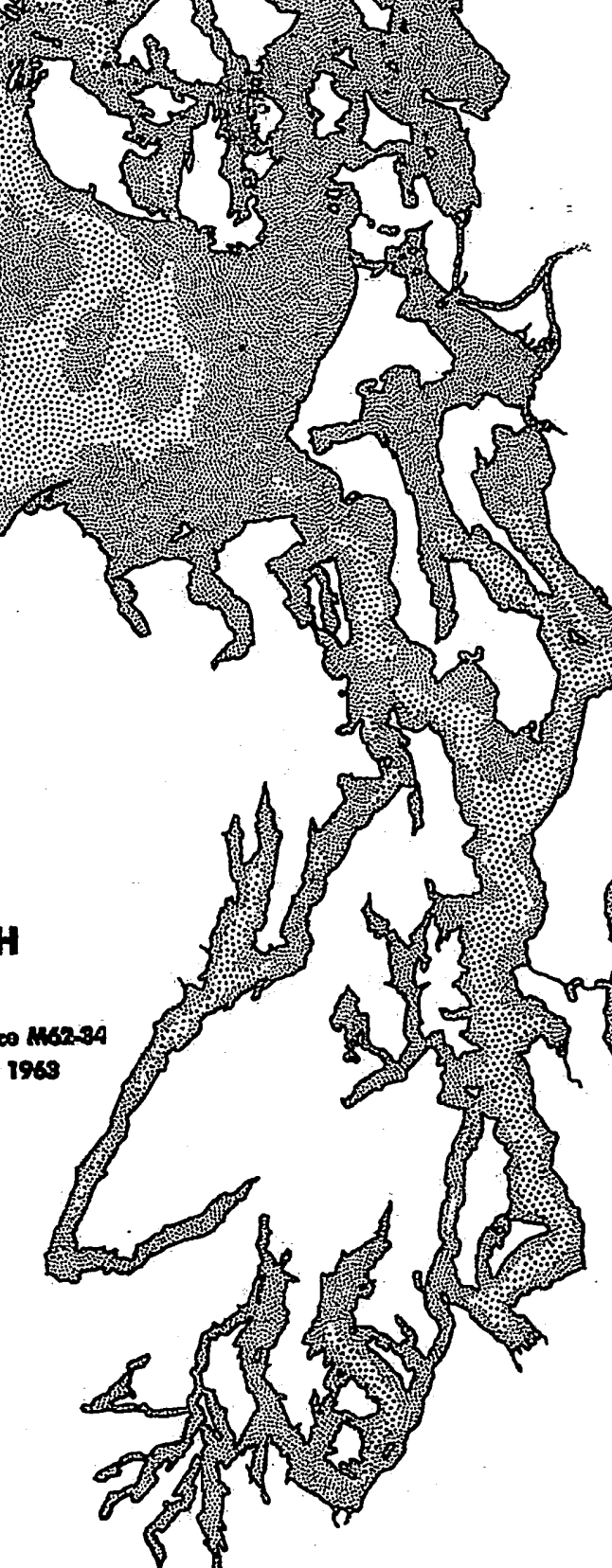


\section{UNIVERSTTY OF HASHINGTON \\ DEPARTMENT OF OCEANOGRAPHY \\ Seatt]e 5, Washington}

Articles Sponsored by the Office of Naval. Research:

Technical Report No. 79

A STMILARITY SOLUTION FOR CIRCULATION IN AS ESTUARY, by Vaurice Rattray, Jr. and Donald V. Hansen. Journal of Marine Research, 20(2):121-133.

Technical Report No. 79

INTERPOLATION ERRORS AND OCEANOGRAPHIC SAMPLING, by Naurice Rattray, Jr. Deep-Sea Research, 2:25-37.

Technical Report No. 80

DISTRIBUTION OF PHYSICAL PROPERTIES BELON THE LEVEL OF SEASONAL INFIUENCE IN THE EASTERN NORTH PACIFIC OCEAN, by Maurice Rattray, Jr., Cuthbert M. Love, and Diane E. Hegearty. Journai of Geophysical Research, 67(3):1099-1107.

Technical Report No. 81

RESEARCH ACTIVITIES AT THF INIVTHSTTY OF WASHTNGTON, DEPARTWENT OF OCEANOGRAPHY, by Karl Banse, Joe S. Creager, Richard H. Fleming and Clifford A. Barnes, Maurice Rattray, Jr., Francis A. Richards. The First, National Coastal and Shallow hater Research Conference, pp. 72:-736.

Technical Report No. 82

NET ZOOPLANKTON AND TOTAL ZOOPLANKTON, by Karl Banse. Rapp. et Proc.-Verb., $153(36): 211-215$.

Technical Report No. 83

A SIMPLE SEMITAUTOMATIC REAGENT DISPENSER, by Ralph W. Riley and Francis A. Richards.

Office of Naval Research

Contracts Nonr-1477(10)

Project Nr 083012
Reference M62-3it

January 1963

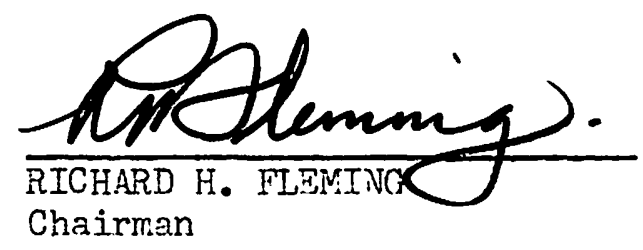




\title{
Distribution of Physical Properties below the Level of Seasonal Influence in the Eastern North Pacific Ocean ${ }^{1}$
}

\author{
Maurice Rattray, JR., Cuthbert M. Love, and Diane E. Heggarty \\ Department of Oceanography, University of Washington, Seatte
}

\begin{abstract}
North-south temperature, salinity, and oxygen sections for the eastern North Pacific Ocean were constructed from data obtained during the 1957 and 1958 cruises of the M.V. Brown Bear and have been compared with data obtained 29 years earlier by the Carnegie. Long-term changes in distribution of these properties have been investigated by using all the pertinent data available for the years between the Carnegie and Brown Bear expeditions. No significant trends appear in the subarctic water; however, there is a possibility of a shifting of the transition zone between the subarctic and equatorial waters.
\end{abstract}

Introduction. In recent years there has been a growing interest in the motion and mixing of the deeper waters of the oceans, an interest which has been stimulated in part by the introduction of new techniques such as isotopic tracers and neutrally buoyant Swallow floats. Concurrently, changes in deep waters have been investigated by comparing values of oceanographic variables observed over a number of years. Sufficient time has now elapsed since the early observations so that, within the limits of accuracy of the measurements, it appears probable that long-term changes in water properties can be evaluated. Worthington [1953, 1954, 1955, 1956] found evidence of warming in the deeper waters of the Arctic and Atlantic oceans and in the Caribbean Sea. A study by Robinson [1960] revealed no long-period changes in the water masses of the North and South Pacific oceans.

A major objective of cruises 176 and 199 of M.V. Brown Bear in 1957 and 1958, as a part of the International Geophysical Year program, was to reoccupy certain Carnegie stations in the North Pacific Ocean (Fig. 1) and to observe any changes which might have taken place in the properties of the deep waters during the 29 -year interval since 1929 .

A comparison of the distributions of physical properties observed during the two periods suggests that real changes may have taken place, but the accuracy of the data is not sufficient to allow us to draw definite conclusions from these two sets of data alone. Therefore, all the data

1 Contribution 243 of the Department of Oceanography, University of Washington. collected in this region during the intervening years have been included in an effort to determine the reality of the apparent long-term changes.

Distributions of temperature, salinity, and oxygen in the Brown Bear section. Figure 1 shows the combined track for cruises 176 and 199 of the Brown Bear. The broken line indicates the Brown Bear section. Vertical sections of temperature, salinity, and oxygen, based on data from these cruises, are shown in Figure 2.

Above $2500 \mathrm{~m}$ there is a general deepening of isotherms toward the south. At depths less than $1000 \mathrm{~m}$ the largest slope of the isotherms occurs between stations 199-8 and 199-29; at depths greater than $1000 \mathrm{~m}$ larger slopes occur both north and south of this region. Below $2500 \mathrm{~m}$ there is no consistent north-south trend in temperature. A temperature minimum occurs at an average depth of $3750 \mathrm{~m}$. An interesting temperature structure that is probably related to the currents through the Aleutian chain is present in the Aleutian trench area at depths less than $1000 \mathrm{~m}$.

In this section, a slight salinity minimum is found between stations 176-30 and 199-27, at each depth in the range 50 to $3000 \mathrm{~m}$. A second minimum occurs in the Aleutian trench area. At depths greater than $3750 \mathrm{~m}$, the salinity is $34.69 \pm .01$ per mil for the entire section. Minimum oxygen concentrations occur at depths between $600 \mathrm{~m}$ and $1000 \mathrm{~m}$. The vertical oxygen gradients above the oxygen minimum are greater to the north of station 199-8 than to the south. For example, the depth of the $1-\mathrm{ml} / 1$ oxygen concentration approximately doubles between 


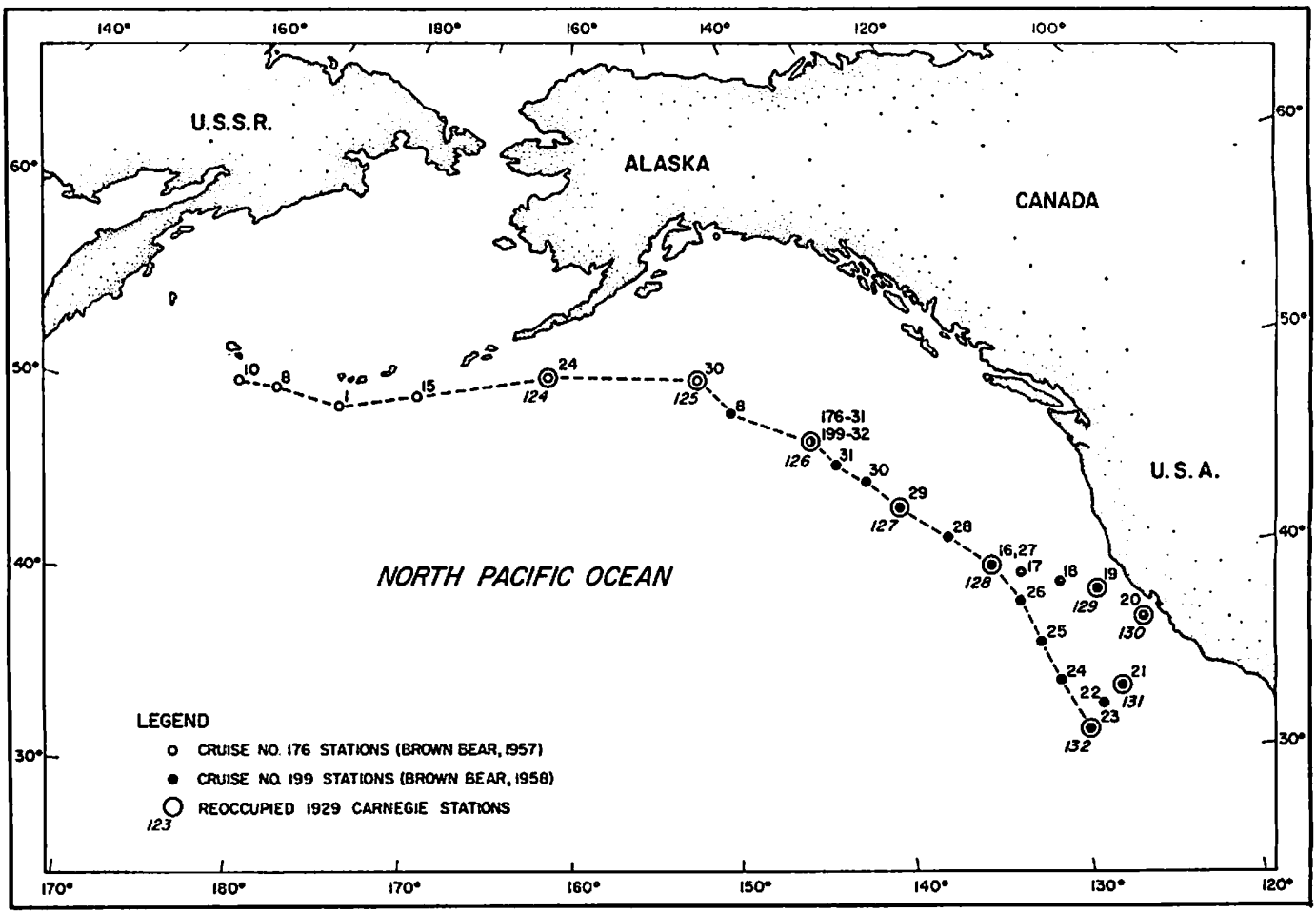

Fig. 1. Station locations Carnegie 1929, Brown Bear 1957 and 1958.

stations 176-30 and 199-8. At all depths below $1500 \mathrm{~m}$, except those in the Aleutian trench area, the lowest oxygen values occur in the region of stations $199-29$ to $199-31$. The distribution of oxygen is more irregular in the Aleutian trench area than elsewhere.

Comparison of Carnegie and Brown Bear temperature and salinity profiles. The Carnegie data [Sverdrup, Fleming, Soule, and Ennis, 1944] extend only to $2500 \mathrm{~m}$ and thus cannot be compared with the more recent observations to determine whether there has been a change in the deep and bottom water of the eastern North Pacific Ocean during the period 1929 to 1958. Above $2500 \mathrm{~m}$ the Carnegie and Brown Bear temperature and salinity profiles are generally similar.

A comparison of the Carnegie and Brown Bear salinities and temperatures shows some differences between the two sets of data, but these differences are neither sufficiently large nor sufficiently clear-cut to positively indicate changes in the water during the intervening period. However, the data do not rule out the possibility that changes have occurred.
Investigation of secular changes in water properties. To investigate further the possibility of secular changes in water properties, all deepwater data for the eastern North Pacific Ocean covering the years 1929 to 1958 were analyzed. Before use, these data were carefully screened and all obviously erroneous values were discarded. It was necessary to restrict consideration to changes occurring above approximately $1500 \mathrm{~m}$ because the accuracy of the data prohibited resolving any differences at greater depths. The most satisfactory method found for characterizing the water properties in this area was the system used by Sverdrup and Fleming [1941] off the coast of southern California. Temperaturesalinity curves for subarctic and equatorial water masses were drawn, and a grid was constructed showing curves of fixed percentages of subarctic water (Fig. 3). Data from the months of March through October (1929-1958) at locations near the Carnegie stations were analyzed to determine the percentages of subarctic water on the surface $\sigma_{t}=27.50$. The results were read with an estimated accuracy of 5 per cent.

There are several advantages in using this 

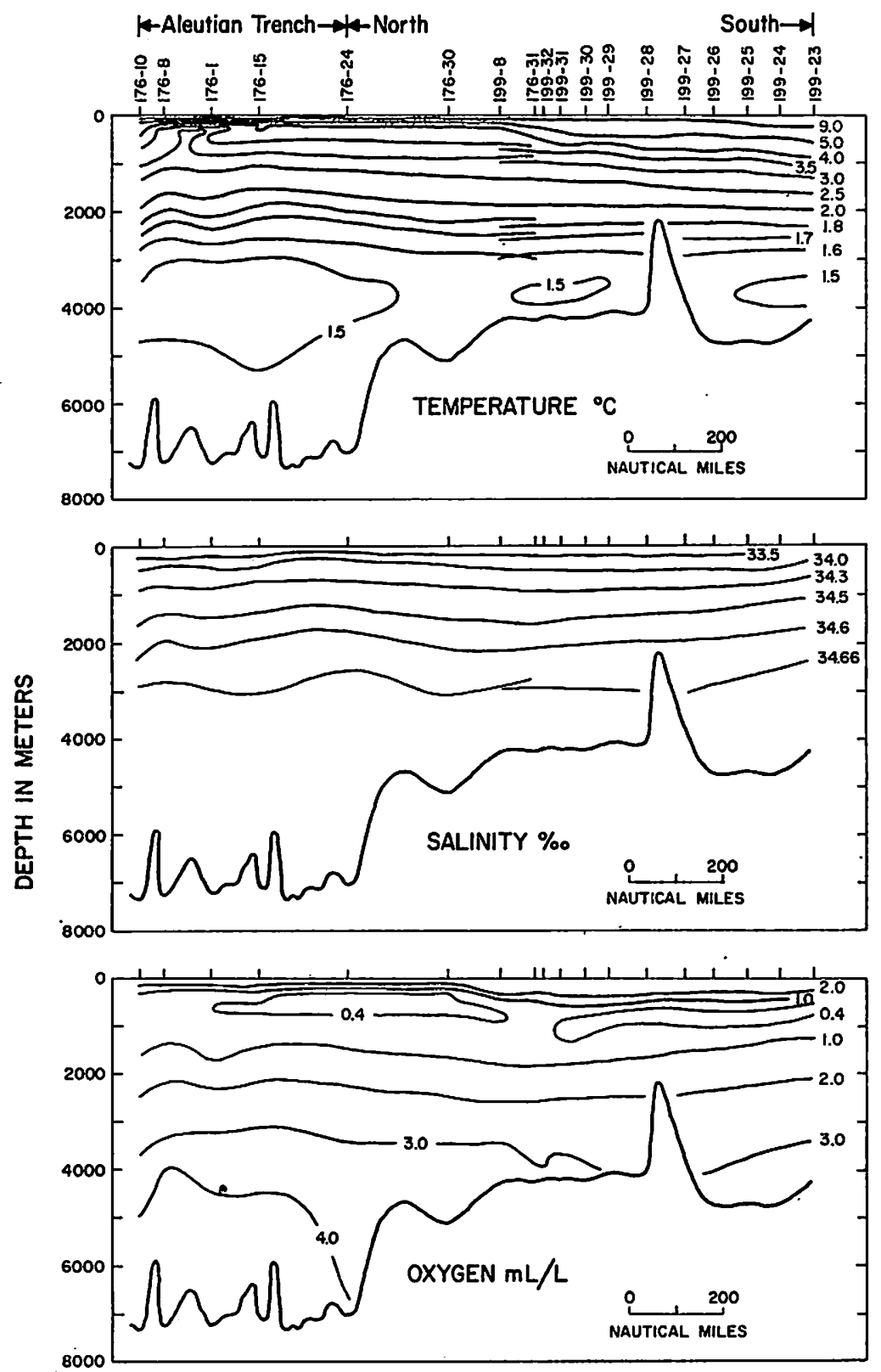

Fig. 2. Distribution of properties in a vertical section along Brown Bear 1957 and 1958 station locations. Top, temperature; center, salinity; bottom, oxygen.

method of analysis. The $T-S$ plot serves to indicate whether an observational point is completely erroneous or lies within the range of instrumental error. If points near a $\sigma_{\imath}$ value of 27.50 are completely erroneous, the data are discarded. However, if the scatter of points about any line lies within the range of normal experimental error, a smooth curve, fitted to these points, is used to improve the estimate of the vertical distribution of the property. The use of percentage of subarctic water rather than salinity at a particular $\sigma_{t}$ value gives a more direct indication of the processes responsible for the distribution of water. That is, a mixture of 


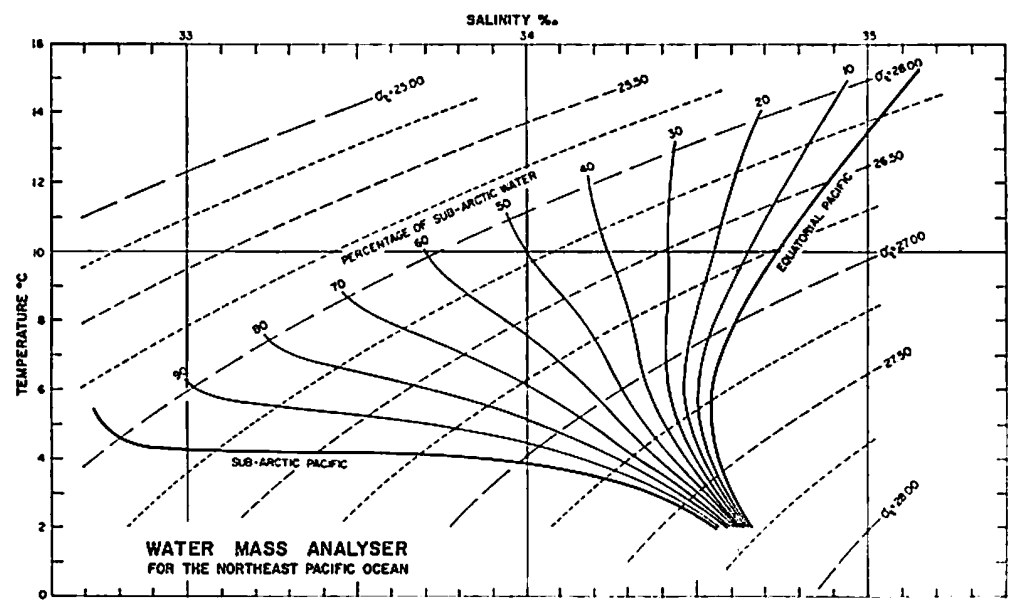

Fig. 3. Water mass analyzer for the eastern North Pacific Ocean.

the two water masses which is independent of depth would be indicated by a percentage of subarctic water constant with depth but not by a value of salinity constant with depth. A change with depth in percentage of subarctic water requires a change with depth in either the advective or mixing processes or possibly a change in both. The determination of the percentage of subarctic water at a particular value of $\sigma_{8}$, rather than at a particular depth, eliminates the variation due to internal waves and errors in depth determination. In judging the significance of any apparent changes in percentage of subarctic water, it must be remembered that, at a $\sigma_{\ell}$ value of 27.50 and within the important percentage range, a 10 per cent change in subarctic water is equivalent to a 0.02 per mil change in salinity at a fixed temperature. Likewise, at a $\sigma_{t}$ equal to 27.25 , a similar 10 per cent change in subarctic water is equivalent to a 0.05 per mil change in salinity at a constant temperature.

The time record of percentage of subarctic water for the Carnegie station locations is shown in Figure 4. The northern stations $(124,125$, and 126) show 100 per cent subarctic water for all years. Farther south and east, the percentages of subarctic water decrease, and there appears to be a year-to-year variability in the amounts occurring at each station. The variations at stations 127 and 128 show a maximum range of 25 per cent but do not indicate any consistent trend. Stations 129 through 132 show a maximum range of 65 per cent, and all have a minimum occurring between the years 1950 and 1955, suggesting that a real change occurred in this area during these years.

Before drawing conclusions on the basis of so few data, a statistical analysis of data was made for four locations: $47^{\circ} \mathrm{N}, 126^{\circ} \mathrm{W} ; 34^{\circ} \mathrm{N}, 128^{\circ} \mathrm{W}$; $33^{\circ} \mathrm{N}, 123^{\circ} \mathrm{W} ; 36^{\circ} \mathrm{N}, 124^{\circ} \mathrm{W}$ (the regions of most intense sampling). The station data were treated as described above to determine the percentage of subarctic water on the $\sigma, 27.25$ and 27.50 surfaces. The percentages of subarctic water at the four locations were obtained by contouring and interpolating the percentages found at surrounding stations (Fig. 5). Compared with the previous results, it is immediately evident that this averaging process has decreased the range of variation found in the percentage of subarctic water. Now, however, points shown on the curves cannot be considered to have equal weight, since they depend upon different numbers of observations.

Because of the paucity of data it is not possible to determine whether the rather large apparent year-to-year fluctuations are significant or whether they are the result of errors in the data. To find whether a long-term trend existed, the data were tested as described below.

All the data for each location were split into two samples, one for the years 1929-1941 and the other for the years 1949-1959. Means and standard deviations were computed for each sample, and then Student's $t$ test [Brooks and Carruthers, 1953] was applied to determine whether the changes in mean values were 

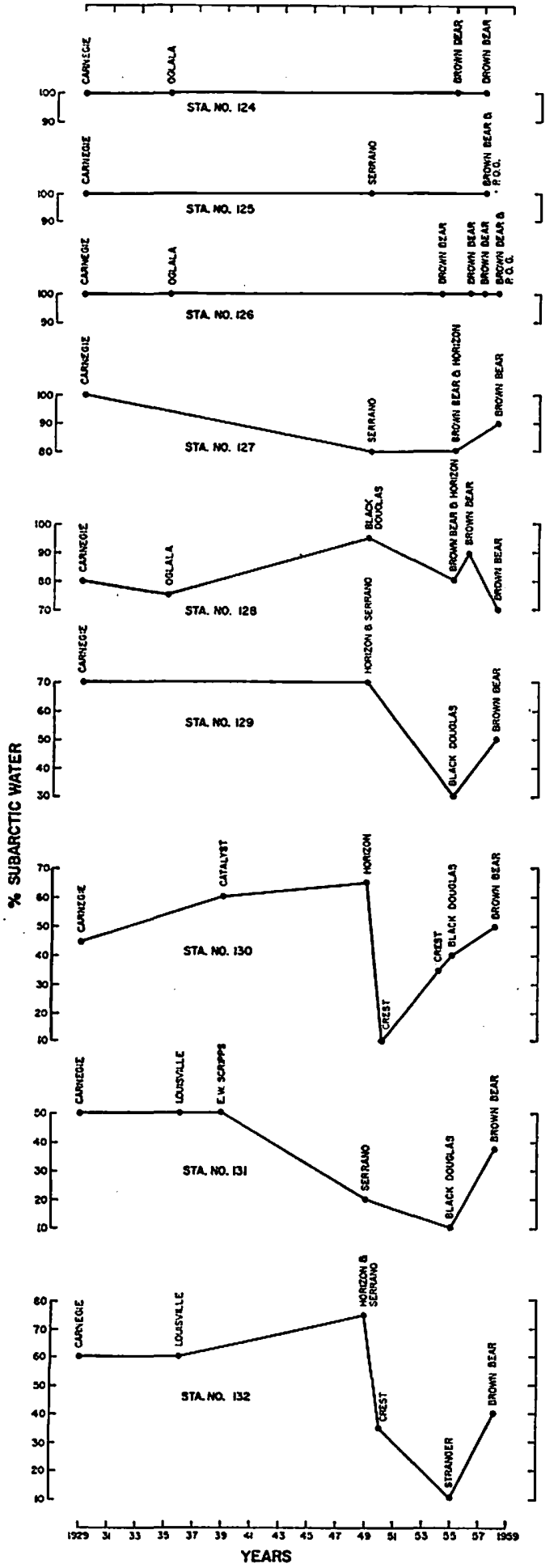

Fig. 4. Percentage of subarctic water at $\sigma_{t}=27.50$ for Carnegie 1929 station locations. significant. The results are shown in Table 1 . Consider, first, the $\sigma_{t} 27.50$ surface: At $47^{\circ} \mathrm{N}$, $126^{\circ} \mathrm{W}$, and at $36^{\circ} \mathrm{N}, 124^{\circ} \mathrm{W}$, the probabilities are greater than 0.1 that the differences in means between the two samples are due to random fluctuations in the data. These findings suggest that there has been no significant change in water composition over this time interval. However, at $34^{\circ} \mathrm{N}, 128^{\circ} \mathrm{W}$, and at $33^{\circ} \mathrm{N}, 123^{\circ} \mathrm{W}$, the similar probabilities are less than 0.01 , and there is the possibility that at these locations the differences between the 1929-1941 and 1949-1959 means represent a real decrease in the percentages of subarctic water. The possibility that a change in calibration standards was the cause of the apparent change in water characteristics is unlikely, since the data for the three locations $-33^{\circ} \mathrm{N}, 123^{\circ} \mathrm{W} ; 34^{\circ} \mathrm{N}, 128^{\circ} \mathrm{W}$; and $36^{\circ} \mathrm{N}, 124^{\circ} \mathrm{W}$-come largely from the same sources, and two of them show a change while the third does not. The results for the $\sigma_{t} 27.25$ surface indicate less change than that noted at the $\sigma_{t} 27.50$ surface. The three northern stations show probabilities greater than or equal to 0.1 that the changes are due to random fluctuations in the data. The southern station at $33^{\circ} \mathrm{N}$, $123^{\circ} \mathrm{W}$, shows a corresponding probability approximately equal to 0.05 .

These results are in agreement with the conclusions of Robinson [1960] that the properties of individual water masses in the North Pacific have remained unchanged during this interval of time, and yet they suggest a displacement of the transition zone between the subarctic and equatorial water masses in the region of the California current. Nevertheless, when the small range of salinity represented by the indicated differences is considered and the fact that the data were not collected in a manner particularly well suited to this type of investigation is taken into account, it is very desirable, before drawing any conclusions, to obtain corroborating evidence of the indicated changes. For this purpose, possible changes in the transport of the California current are investigated. $x$

Transport in the California current system. A change in the percentage of subarctic water off the coast of southern California could result from a change in the transport of the California current system. To test this hypothesis for the apparent change observed, the geostrophic transports in this system were calculated from the 

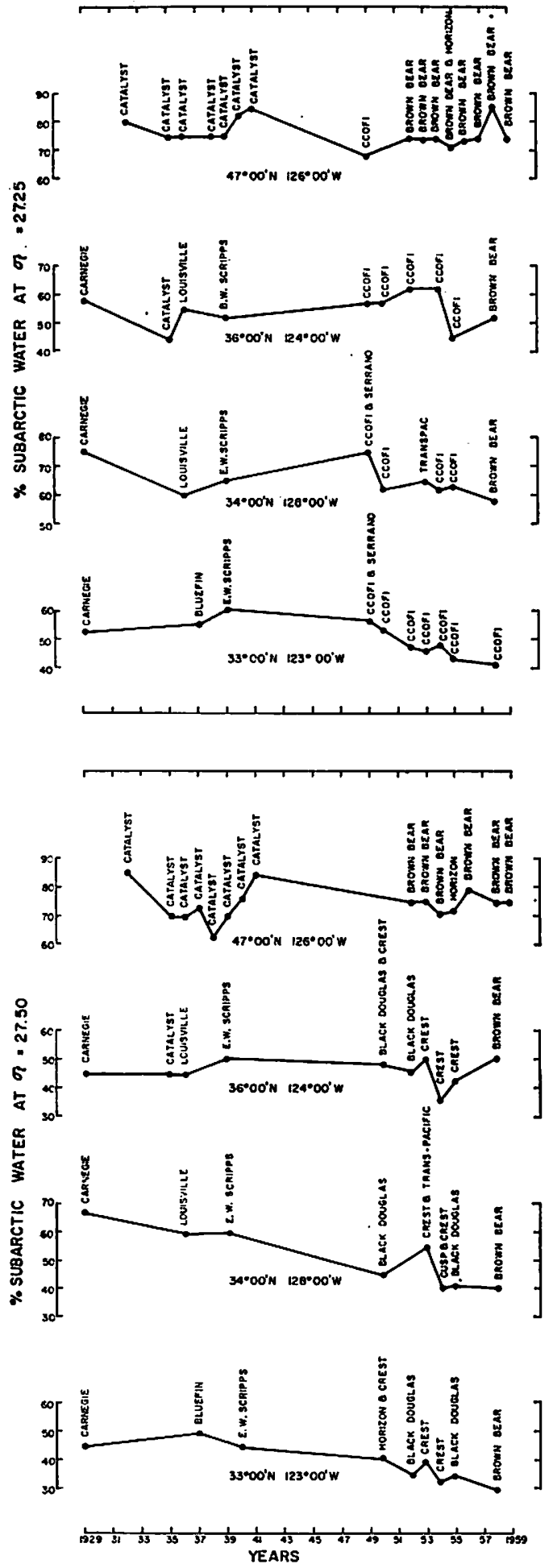

Fig. 5. Percentage of subarctic water at $\sigma_{t}=27.25$ and at 27.50 for four locations in the castern North Pacific Occan.
Brown Bear and Carnegie data and the results compared. The choice of a reference level for this calculation appears rather arbitrary on the basis of the data alone. A reference level of $2000 \mathrm{~m}$ was selected, as it is the greatest depth for which data were available at all the stations.

Figure 6 shows the transports per unit depth across five sections bounding the triangular area enclosed by the southern portion of the Brown Bear cruise track. Computations indicate that the transport in the upper $500 \mathrm{~m}$ is to the south and east across all sections except Carnegie section A. Here, a strong circulation around station 129 is indicated. The question whether this is real or an effect of errors in the station data has not been resolved and is unimportant for the present study.

The Brown Bear data for sections A and C show a reverse flow between 700 and $2000 \mathrm{~m}$. With the exception of section $A$, the Carnegie transports show larger southeasterly, southerly, and easterly components between 700 and $1200 \mathrm{~m}$ than those obtained for the Brown Bear. Within this depth range, the difference in transport is such that a lesser percentage of subarctic water is to be expected during the latter period. Section $\mathrm{C}$ is the most significant with respect to changes in water properties at the locations $33^{\circ} \mathrm{N}, 123^{\circ} \mathrm{W} ; 34^{\circ} \mathrm{N}, 128^{\circ} \mathrm{W}$; and $36^{\circ} \mathrm{N}, 124^{\circ} \mathrm{W}$. Here, even though the $2000-\mathrm{m}$ reference level is completely arbitrary, the magnitude of the difference in the transport curves from the Brown Bear and the Carnegie data between the depths of 700 and $1200 \mathrm{~m}$ suggests the likelihood of northwesterly flow during the Brown Bear year in contrast to southeasterly flow during the Carnegie year. The northwesterly flow has a maximum at about $1500 \mathrm{~m}$ and goes to zero at 700 and $2000 \mathrm{~m}$. From these data the greatest change in the percentage of subarctic water would be expected to occur near the $\sigma, 27.50$ surface which lies between $1000 \mathrm{~m}$ (the depth of maximum southeasterly flow in the Carnegie year) and $1500 \mathrm{~m}$ (the depth of maximum northwesterly flow in the Brown Bear year). The $\sigma_{t}$ 27.25 surface lies at about $700 \mathrm{~m}$, where no northwesterly flow is indicated in the Brown Bear year. Thus, while the difference in the transport between the Carnegie and the Brown Bear years at this depth should indicate that some change would be expected in the percentage of subarctic water, it is evident that this change 
TABLE 1. Means and Standard Deviations of Percentage of Subarctic Water

\begin{tabular}{|c|c|c|c|c|c|c|c|}
\hline \multirow[b]{2}{*}{ Locution } & \multicolumn{2}{|c|}{$1929-1941$} & \multicolumn{2}{|c|}{$1949-1958$} & \multirow[b]{2}{*}{$t$} & \multirow[b]{2}{*}{$\begin{array}{l}\text { Degrees of } \\
\text { Freedom }\end{array}$} & \multirow[b]{2}{*}{ Probability } \\
\hline & Mean & $\begin{array}{l}\text { Standard } \\
\text { Deviation }\end{array}$ & Mean & $\begin{array}{l}\text { Standard } \\
\text { Deviation }\end{array}$ & & & \\
\hline \multicolumn{8}{|c|}{$\sigma_{t}=27.50$} \\
\hline $\begin{array}{l}47^{\circ} \mathrm{N}, 126^{\circ} \mathrm{W} \\
36^{\circ} \mathrm{N}, 124^{\circ} \mathrm{W} \\
34^{\circ} \mathrm{N}, 128^{\circ} \mathrm{W} \\
33^{\circ} \mathrm{N}, 123^{\circ} \mathrm{W}\end{array}$ & $\begin{array}{l}74.0 \\
46.2 \\
62.3 \\
46.7\end{array}$ & $\begin{array}{l}7.7 \\
2.5 \\
4.0 \\
2.9\end{array}$ & $\begin{array}{l}74.4 \\
44.8 \\
44.2 \\
35.7\end{array}$ & $\begin{array}{l}3.0 \\
5.3 \\
5.8 \\
4.2\end{array}$ & $\begin{array}{l}0.12 \\
0.48 \\
4.3 \\
4.0\end{array}$ & $\begin{array}{r}13 \\
8 \\
6 \\
7\end{array}$ & $\begin{aligned} p & >0.1 \\
p & >0.1 \\
0.01>p & >0.001 \\
0.01>p & >0.001\end{aligned}$ \\
\hline \multicolumn{8}{|c|}{$\sigma_{t}=27.25$} \\
\hline $\begin{array}{l}47^{\circ} \mathrm{N}, 126^{\circ} \mathrm{W} \\
36^{\circ} \mathrm{N}, 124^{\circ} \mathrm{W} \\
34^{\circ} \mathrm{N}, 128^{\circ} \mathrm{W} \\
33^{\circ} \mathrm{N}, 123^{\circ} \mathrm{W}\end{array}$ & $\begin{array}{l}78.1 \\
52.2 \\
66.7 \\
55.7\end{array}$ & $\begin{array}{l}3.9 \\
5.2 \\
6.3 \\
3.4\end{array}$ & $\begin{array}{l}74.1 \\
55.8 \\
64.2 \\
47.7\end{array}$ & $\begin{array}{l}4.3 \\
5.9 \\
5.3 \\
4.9\end{array}$ & $\begin{array}{l}1.8 \\
0.88 \\
0.56 \\
2.3\end{array}$ & $\begin{array}{r}14 \\
8 \\
7 \\
8\end{array}$ & $\begin{array}{l}p=0.1 \\
p>0.1 \\
p>0.1 \\
p=0.05\end{array}$ \\
\hline
\end{tabular}
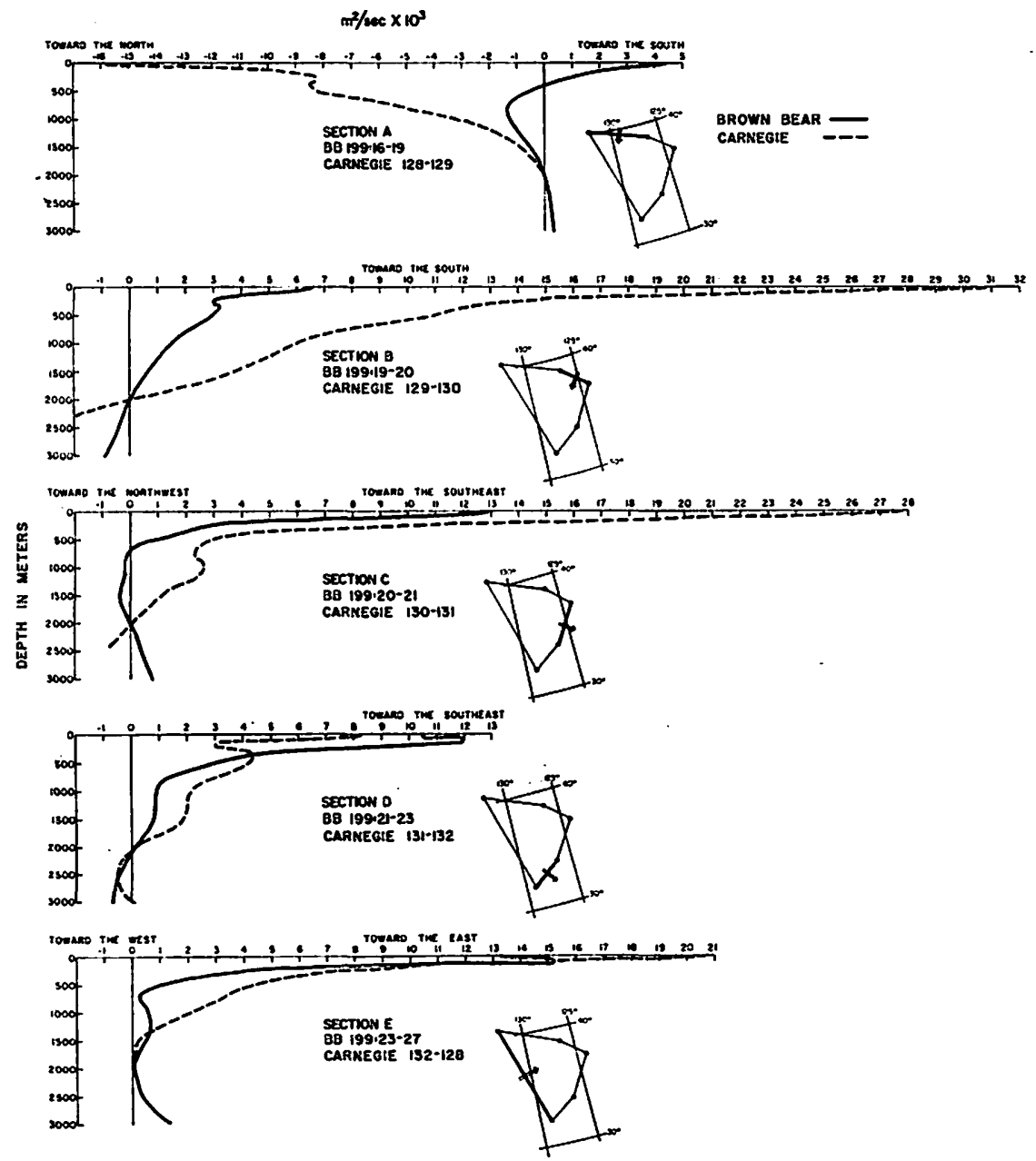

Fig. 6. Transport in $\mathrm{m}^{2} / \mathrm{sec} \times 10^{3}$ per unit depth in the California current for the years 1929 and 1958. 
should not be as large as that found at greater depth.

With such limited data available on the transports during the years 1929 and 1958, it is not possible to explain why the changes in percentage of subarctic water should appear at $33^{\circ} \mathrm{N}, 123^{\circ} \mathrm{W}$, and $34^{\circ} \mathrm{N}, 128^{\circ} \mathrm{W}$, but not at $36^{\circ} \mathrm{N}, 124^{\circ} \mathrm{W}$. However, the transports for these two years do lend support to the hypothesis that a decrease in the percentage of subarctic water occurred at these locations during this 29 -year period.

It is interesting to speculate on the probable causes of the variations in the California current system. Reid, Roden, and Wyllie [1958] have discussed this point and have shown that there was a greater northerly component of wind off the California coast during the period 1950-1956 than during the period 1920-1938.

To determine the effects of this change in the wind it is necessary to review briefly the dynamics of the California current system. Munk [1950] has shown that the transport of the California current system can be related to the curl of the wind stress. The wind in this region is prevailing northwest with a maximum velocity located several hundred kilometers off shore. The transport in the California current system, accordingly, must be southerly to the west of this wind stress maximum and must have a northerly component inshore of this maximum. The total transport, as determined by the curl of the wind stress, is composed of two parts: (1) the Ekman drift due to the surface wind stress and (2) the geostrophic transport. With northwest winds, the Ekman transport will be directed toward the southwest, and thus, with northerly or even zero total transport, there must be a northerly component of geostrophic transport. This condition is realized with a southerly component of geostrophic flow in the surface layers and a reversal in the direction of geostrophic flow at depth. Since an increase in the wind stress will probably increase the magnitude but not the distribution of the wind-stress curl, an increase in the northerly component of wind will increase the southwesterly Ekman transport and the magnitude of the southerly and northerly total transports. Under these conditions it is evident that, for an increase in the northerly component of wind, the geostrophic transport in the countercurrent region must show an increased transport toward the north, which occurs predominantly below the surface layers. There is thus a good correlation between the change in wind and the change in the geostrophic flow of the California current occurring between 1929 and 1958. However, a quantitative relationship awaits a much more thorough investigation of the whole question.

Conclusions. A comparison of conditions in the eastern North Pacific Ocean during the years between 1929 and 1958 shows that the properties of specific water masses have not changed. However, a shift in the transition zone between subarctic and equatorial water off the coast of California is suggested by changes in the water properties at adjacent locations. This change correlates with a decrease in the southeasterly component of flow of deeper water in the California current system. It appears that changes in the flow of the California current system correlate with changes in the local wind patterns, but more work remains to be done on this relationship.

The major difficulty in our analysis has been the lack of any systematic sampling of the deeper waters in this region. Deep stations have been occupied infrequently, and not at all on a regular basis suitable for a time-series study. Nevertheless, it has been shown that long-term changes in water properties can be expected which correlate with wind-induced changes in the California current system and that an understanding of the effect of the wind on the California current system cannot be based upon changes occurring in the surface layers alone but account must be taken of the changes occurring at depth.

Acknowledgments. This paper represents work carried out by the Department of Oceanography of the University of Washington under contract with the National Science Foundation, project NSF 21.6, and with the Office of Naval Research, contract Nonr 477(10), project NR 083012 . We wish to acknowledge the assistance of members of the Data Analysis Section, University of Washington $\mathrm{De}-$ partment of Oceanography, in preparing graphs and making calculations.

\section{REFERENCES}

Brooks, C. E. P., and N. Carruthers, Handbook of Statistical Methods in Meteorology, Her Majesty's Stationery Office, London, pp. 64-67, 1953.

Munk, W. H., On the wind-driven ocean circulation, J. Metsorol., 7, 79-93, 1950.

Reid, J. L., Jr., G. I. Roden, and J. G. Wyllie, 
Studies of the California current system, California Cooperative Oceanic Fisheries Investigations, Progress Repl. 1 July 1956 to 1 January 1958, Marine Research Committee, State of Californit Department of Fish and Game, pp. 29-55, 1958.

Robinson, M. K., Statistical evidence indicating no long-term climatic change in the deep waters of the North and South Pacific oceans, J. Geophys. Research, 65, 2097-2116, 1960.

Sverdrup, H. U., and R. H. Fleming, The waters off the coast of southern California, March to July 1937, Bull. Scripps Inst. Oceanog. Tech. Ser., $4(10), 261-378,1941$.

Sverdrup, H. U., J. A. Fleming, F. M. Soule, and C. C. Ennis, Scientific Results of cruise VII of the Carnegie during 1928-1929 under command of Captain J. P. Ault, Oceanography-I-A, Observations and results in physical oceanography, Carnegie Inst. Wash. Publ. 546.156 pp., 1944.

Worthington, L. V., Oceanographic results of project Skijump I and Skijump II in the polar sea, 1951-1952, Trans. Am. Geophys. Union 34(4), 543-551, 1953.

Worthington, L. V., A preliminary note on the time scale in North Atlantic circulation, Deep-Sea Research, 1, 244-251, 1954.

Worthington, L. V., A new theory of Caribbean bottom-water formation, Deep-Sea Research, 3 , 82-87, 1955.

Worthington, L. V., The temperature increase in the Caribbean deep water since 1933, Deep-Sea Research, \$, 234-235, 1956.

\section{SoURCES OF DATA}

Fleming, J. A., C. C. Ennis, H. U. Sverdrup, S. L. Seaton, and W. C. Hendrix, Scientific results of cruise VII of the Carnegie during 1928-1929 under command of Captain J. P. Ault, Oceanography-I-B, Observations and results in physical oceanography, Carnegie Inst. Wash. Publ., 545, 315 pp., 1945.

Goodman, Joe, and Thomas G. Thompson, Characteristics of the waters in sections from Dutch Harbor, Alaska, to the Strait of Juan de Fuca and from the Strait of Juan de Fuca to Hawaii, Univ. Wash. Publs. in Oceanog., 3, 81-103, 1940.

Pacific Oceanographic Group of the Fisheries Research Board of Canada. Data reports: Physical, Chemical and Plankton Data Record, August 15, 1957; Manuscript Report Series, no. 29. Rakestraw, Norris W., Paul L. Horrer, and Warren S. Wooster (eds.), Oceanic Observations of the Pacific, Scripps Institution of Oceanography. University of California Press, Volumes for 1949, 1950, NORPAC (1955).

Scripps Institution of Oceanography, University of California. Data reports: SIO References 52-37, $56-24,56-27,57-10,58-15,58-44,58-65,59-15$, 59-33.

Sverdrup, H. U., and staff, Oceanographic Observations of the Scripps Institution in 1989, University of California Press, Berkeley, 1(2), 1943.

U. S. S. Louisville, U. S. S. Fieberling, and U. S. S. Serrano (Unpublished manuscript data, Scripps Institution of Oceanography).

University of Washington Department of Oceanography, Data reports: Tech. Repts. 49, 55, 66; Spec. Repts. 28, 29, 30.

(Manuscript received June 12, 1961; revised December 26, 1961.) 